Esta obra forma parte del acervo de la Biblioteca Jurídica Virtual del Instituto de Investigaciones Jurídicas de la UNAM

www.juridicas.unam. $m x$

\title{
Anotaciones sobre la inconstitucionalidad del voto electrónico en Alemania*
}

\section{Julio Téllez Valdés**}

\section{Sumario:}

I. Antecedentes

II. Características primordiales de la sentencia 2BVC 3/072BVC 4/07 de la Corte Constitucional Federal de Alemania (Sentencia del segundo Senado del 3 de marzo de 2009)

III. Argumentos presentados en contra del uso de las urnas electrónicas

IV. Argumentos presentados a favor del uso de las urnas electrónicas

V. Principales implicaciones.

* Sentencia $2 \mathrm{BvC}$ 3/07-2BvC 4/07 de la Corte Constitucional Federal de Alemania (Sentencia del Segundo Senado del 3 de marzo de 2009). Traducción y comentarios der los profesores argentinos Manfredo Koessl y José Pérez Corti. Véase http://www.jo seperezcorti.com.ar/Archivos/Comentarios_a_Fallos/20100709_S_2BvC3_07_BvC4_07_ EVote_Alemania_Traduccion_Koessl_y_comentario_PerezCorti_JE_o6_2010_Mx.pdf. Enriquecidos por las matizaciones del Prof. Colombiano Tulio Elí Chinchilla, véase http://www.elespectador.com/columna137468-inconstitucionalidad-del-voto-electroni co-alemania. De igual forma véase texto original de la sentencia en alemán: http://www. bverfg.de/entscheidungen/cs20090303_2bvco00307.html. Todos los documentos revisados en septiembre de 2011.

** Doctor en Derecho Informático; investigador en el Instituto de Investigaciones Jurídicas de la UNAM. 


\section{Antecedentes}

a) En la década de los cincuenta se intentó en Alemania reemplazar el proceso electoral tradicional del conteo manual de boletas por métodos más racionales y el empleo de equipos electorales. Según artículo 35, párrafo 3, de la Ley Electoral Federal del 7 de mayo de 1956 (BGBl I S. 383 - BWG) el ministro del Interior del Bund podía permitir que, en lugar de boletas electorales, se utilizaran equipos de conteo electoral oficialmente autorizados. Sobre esta base se promulgó la prescripción sobre la utilización de equipos de conteo electoral para elecciones para el Bundestag Alemán del 24 de agosto de 1961.

b) En las elecciones para el 16o. Bundestag alemán, aproximadamente dos millones de electores de Brandenburg, Hessen, NordrheinWestfalen, Rheinland-Pfalz y Sachsen-Anhalt dieron su voto por medio de los equipos electorales guiados por computadora, producidas por la empresa holandesa Nedap y distribuidas en Alemania desde 1999 como componente central del "Sistema electoral integral" (IWS) por la empresa H. GmbH.

c) Para las elecciones para el $16^{\circ}$ Bundestag Alemán estaba en vigencia el $₫ 35$ BWG en la versión de la publicación de la Ley Electoral Federal del 23 de julio de 1993 (BGBl I S. 1288, ber. S. 1594), modificada por última vez por la Octava Ordenación de Adaptación de Competencia del 25 de noviembre de 2003 (BGBl I p. 2304).

La prescripción tiene el siguiente texto: $16 \S 35$ Votación con equipos electorales.

(1) Para facilitar la emisión y contabilización de los votos pueden utilizarse equipos electorales en lugar de urnas electorales y boletas electorales.

(2) Los equipos electorales en el sentido del inc. 1 deben garantizar el secreto de la votación. Su versión debe ser admitida oficialmente para la utilización en elecciones para el Bundestag alemán o en general. Sobre su admisión decide el Ministerio del Interior a solicitud del fabricante del aparato electoral. La utilización de un aparato electoral admitido oficialmente debe ser autorizada por el Ministerio del Interior. La autorización se puede otorgar para una determinada elección o en general.

(3) Se autoriza al Ministerio del Interior, por medio de ordenamientos jurídicos que no necesitan de la ratificación del Bundesrat, dar prescripciones sobre: 
1) Las condiciones para la admisión oficial de las versiones de equipos electorales, así como la retractación o revocación de la admisión.

2) El procedimiento para la admisión oficial de una versión.

3) El procedimiento para el examen de un aparato electoral en el modelo sobre la versión oficialmente admitida.

4) La prueba pública de un aparato electoral antes de su utilización,

5) El procedimiento para el permiso oficial de la utilización así como la retractación y la revocación del permiso.

6) De las particularidades implicadas en la utilización de equipos electorales en relación con la elección.

d) El empleo de los equipos electorales no fue compatible con el artículo 38 en relación con el artículo 20, párrafos 1 y 2, de la Constitución en la medida en que no asegura ningún control acorde al principio de la publicidad de la elección.

\section{Características primordiales de la sentencia 2bvc 3/07 - 2bvc 4/07 de la Corte Constitucional Federal de Alemania (sentencia del segundo Senado del 3 de marzo de 2009)}

a) El principio de la publicidad de la elección del artículo 38 en relación con el artículo 20, párrafos 1 y 2, ordena que todos los pasos esenciales de la elección están sujetos al control público, en la medida en que otros intereses constitucionales no justifiquen una excepción.

Artículo 20 de la Constitución alemana [Fundamentos del orden estatal, derecho de resistencia]

(1) La República Federal de Alemania es un Estado federal democrático y social.

(2) Todo poder del Estado emana del pueblo. Este poder es ejercido por el pueblo mediante elecciones y votaciones y por intermedio de órganos especiales de los poderes legislativo, ejecutivo y judicial.

(3) El poder legislativo está sometido al orden constitucional; los poderes ejecutivo y judicial, a la ley y al Derecho.

(4) Contra cualquiera que intente eliminar este orden todos los alemanes tienen el derecho de resistencia cuando no fuere posible otro recurso. 
Artículo 38 de la constitución alemana

(1) Los diputados del Bundestag alemán serán elegidos por sufragio universal, directo, libre, igual y secreto. Son los representantes del pueblo en su conjunto, no ligados a mandatos ni instrucciones, y sujetos únicamente a su conciencia.

(2) Tiene derecho de voto quien haya cumplido dieciocho años de edad. Es elegible quien haya cumplido los años con los cuales se alcanza la mayoría de edad.

(3) La regulación se hará por una ley federal ${ }^{1}$

Artículo 41 de la ley electoral alemana

(1) El control de las elecciones compete al Bundestag. Decide también si uno de sus miembros ha perdido su calidad de tal.

(2) Contra la decisión del Bundestag se admite el recurso de queja ante la Corte Constitucional Federal.

(3) La regulación se hará por una ley federal.

b) En la utilización de equipos electorales electrónicos, el ciudadano debe poder controlar los pasos esenciales del acto electoral y la determinación del resultado de manera fiable y sin conocimientos técnicos especiales.

\section{Argumentos presentados en contra del uso de estas urnas electrónicas}

Basados en la Ley Electoral Federal y la Ordenación Federal de Equipos Electorales se objetó la autorización y utilización de dispositivos electrónicos electorales en general y de los equipos Nedap en particular. Se solicitó la anulación de la votación en 30 circuitos electorales en Brandenburg, Hessen, Nordrhein-Westfalen, Rheinland-Pfalz und Sachsen-Anhalt arguyendo que la utilización de equipos electorales guiados por computadora atenta contra el principio de la publicidad de la elección y el principio de la oficialidad de la elección.

En este sentido, el principio de publicidad debe garantizar una realización ordenada de la elección y garantizar la correcta integración del Parlamento. El control debe hacer hincapié en el secreto del voto y que

1 Véase http://constitucion.rediris.es/legis/legextr/ConstitucionAlemana.html. 
éste no se pueda modificar, que el resultado sólo debe contabilizar los votos emitidos. La utilización de los equipos electorales impugnados impide un control efectivo por parte del público y la junta electoral, ya que la determinación del resultado se realiza en el interior del aparato electoral. Según lo cual, la publicidad de una elección con equipos electorales sólo puede garantizarse con mecanismos de control como por ejemplo la impresión de un protocolo en papel del voto emitido.

Por otra parte se esgrimió que "la confiabilidad de los software instalados en los equipos electorales no son controlables por el público, el peligro especial de los equipos electorales guiados por computador consiste en que la manipulación de las elecciones puede ser realizada mucho más eficazmente que en elecciones con urnas tradicionales. Estas manipulaciones pueden consistir en otorgar los votos a partidos independientemente de la decisión del elector, o repartirlos entre los partidos según una proporción previamente fijada. Estas manipulaciones pueden ser realizadas por los empleados como por terceros por vía de virus o troyanos, los que pueden resultar indetectables.

Por otra parte, se manifestó por parte de los recurrentes que el uso de equipos electorales guiados por computador se opone al principio de democracia, al principio del Estado de derecho y los principios de publicidad y oficialidad de las elecciones. Ni el $\S 35$ BWG ni el Ordenamiento de Equipos Electorales Federal bastan a los principios constitucionales sobre elecciones de la publicidad y la oficialidad, solicitándose la anulación de las elecciones en los distritos referidos, así como la publicación de la documentación sobre la que se autorizó el empleo de dichos equipos.

\section{Argumentos presentados a favor del uso de las urnas electrónicas}

El Ministerio del Interior se defendió argumentando que

la publicidad del acto de votación es garantizada con el uso de equipos electorales. Los ciudadanos pueden controlar que sólo electores autorizados tengan acceso a la cabina de votación. La junta electoral puede controlar, por medio de la lectura de la unidad de funcionamiento, que cada elector sólo vote una vez. 
En general, el principio de publicidad no es ilimitado, ya que está en conflicto con el objetivo de conformar una representación popular con capacidad operativa en poco tiempo.

La ley Electoral Federal valoriza el objetivo de hacer que la elección se realice en el tiempo adecuado y se establezca el resultado electoral en un tiempo prudencial, en una importancia más grande que el minucioso control del público.

La publicidad está garantizada, el público puede controlar la impresión del resultado electoral al finalizar el acto y el observador electoral y la junta electoral pueden cotejar los resultados.

Se cumplieron con las normas (Ordenamiento Federal de Equipos Electorales, ylas directivas para los tipos de construcción de Equipos Electorales). Es posible manipular los equipos en teoría, pero en la práctica resulta muy difícil. No hay indicios de manipulación o modificaciones involuntarias en las elecciones impugnadas.

El principio de publicidad es exagerado si se solicita que cualquiera deba poder comprender la totalidad del hecho electoral, inclusive las preparaciones electorales hasta en las ramificaciones de los detalles técnicos y que la totalidad del accionar estatal en una elección, incluyendo los permisos de versiones de equipos electorales así como que los demás preparativos de los órganos electorales y otras instituciones, estén bajo control público.

Finalmente el Ministerio manifestó que no puede darse una sobrevaloración de los requisitos técnicos de seguridad. No se puede garantizar la seguridad absoluta frente a falsificaciones electorales. Las elecciones con urnas manuales y el voto por correo también son teóricamente manipulables. Las posibilidades de manipulación con computadoras no se diferencian de los peligros en elecciones tradicionales.

\section{Principales implicaciones}

Manfredo Koessl y José Pérez Corti nos dicen que la utilización de mecanismos computarizados de votación y escrutinio cuyos pasos y procesos no pueden ser comprendidos, controlados y revisados por el ciudadano raso ( $\sin$ conocimientos técnicos especializados) y $\sin$ 
un soporte material independiente del informático, es incompatible con el principio de publicidad del proceso electoral, consagrado en el artículo 38 de la ley fundamental de ese país.

La sentencia no descalifica el voto electrónico en sí mismo. Simplemente declara inconstitucional la prescripción de utilizar equipos electorales en las elecciones del Bundestag y la representación ante el Parlamento europeo. Ello por cuanto

Los equipos no tenían previsto la posibilidad de un registro de los votos independiente del módulo de memoria de votos, que le permitiese a cada elector la verificación de su votación.

Aunque no mediaba ninguna sospecha de fraude (no se aceptó anular los casi 2000000 de votos emitidos electrónicamente), la sola existencia de una barrera técnica que bloquea el control ciudadano sobre el procesamiento de la voluntad electoral tornaba inaceptable el mecanismo. La sustentación de tal celo parece convincente:

Ya que el escrutinio es objeto de un proceso de elaboración de datos realizado exclusivamente en el interior de los equipos electorales, ni los órganos electorales ni los ciudadanos que asisten a la determinación del resultado electoral pueden comprender si los votos válidos emitidos han sido adjudicados correctamente a las ofertas electorales y si los votos obtenidos por las ofertas electorales individuales han sido indagados correctamente.

En tales circunstancias — según la providencia- "un recuento público, por el que los ciudadanos pudieran comprender confiablemente y por sí mismos, y sin conocimientos especiales previos quedaba así excluido". 